\title{
Sickness absence in the Whitehall II study, London: the role of social support and material problems
}

Elizabeth G S Rael, Stephen A Stansfeld, Martin Shipley, Jenny Head, Amanda Feeney, Michael Marmot

\begin{abstract}
Study objective - To investigate the role of social supports, social networks, and chronic stressors: (i) as predictors of sickness absence; and (ii) as potential explanations for the socioeconomic gradient in sickness absence.

Design - A prospective cohort study (Whitehall II study) with sociodemographic factors, health and social support measured at baseline, and spells of sickness absence measured prospectively.

Setting - Twenty London based non-industrial departments of the British civil service.
\end{abstract}

Participants - Participants were civil servants $(n=10308)$, aged $35-55$ years at baseline, of whom $67 \%(6895)$ were men and $33 \%$ (3413) were women. The overall response rate for Whitehall II was $73 \%$ (74\% for men and $71 \%$ for women). The analysis is based on $41 \%$ of the sample who had data on reasons for sickness absence and were administered all social support questions. Only $4 \cdot 3 \%$ of participants did not complete all necessary questions and were excluded.

Measurements and main results - High levels of confiding/emotional support from the "closest person" predicted higher levels of both short and long spells of sickness absence. After adjusting for baseline physical and psychological health the effects were increased, suggesting that high levels of confiding/emotional support may encourage illness behaviour rather than generate illness. Social network measures showed a consistent but less striking pattern. Increased levels of negative aspects of social support resulted in higher rates of sickness absence. Material problems strongly predicted sickness absence, but the effect was diminished once adjustment for the covariables was made, suggesting that health status may be functioning as an intervening variable between chronic stressors and sickness absence. In addition, social support may buffer the effects of chronic stressors. Social support did not contribute to explaining the gradient in sickness absence by employment grade beyond that explained by the baseline covariables.

Conclusions - Sickness absence from work is a complex phenomenon, combining illness and coping behaviours. High levels of confiding/emotional support, although not entirely consistent across samples, may either encourage people to stay at home when they are ill or may be accompanied by more social obligations at home prolonging sickness absence. Negative aspects of close relationships may jeopardise health and hence increase sickness absence.

\section{( $\mathcal{F}$ Epidemiol Community Health 1995;49:474-481)}

Social support, measured as social network contacts, is predictive of lower mortality in

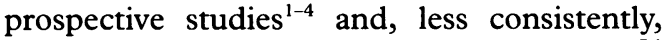
with lower levels of physical morbidity. ${ }^{56}$ Different measures of support and different outcomes may have contributed to this inconsistency. Little is known about the influence of social support on illness related behaviours such as sickness absence from work beyond the influence of marital status, where divorced and widowed persons take more absence. ${ }^{78}$

Social support has been measured in both quantitative and qualitative terms, ${ }^{910}$ and sometimes these are not clearly distinguished. It has been suggested that social support has two major mechanisms of action: either a direct influence on health or a buffering influence on health moderating the impact of environmental stressors. ${ }^{11-13}$ The effects of social support may differ depending on gender and socioeconomic status.

Sickness absence is a composite outcome, comprising health and social behaviour, which is most valid as a measure of ill health for longer spells of absence. ${ }^{14}$ It is primarily a proxy measure of ill health implying reduced occupational functioning but can also be seen as a social outcome, a form of illness behaviour, leading to withdrawal from work, which may be linked to a wide range of life stressors and may be influenced by social support.

In the Whitehall II study, a prospective study of psychosocial influences on health in an occupational cohort, qualitative and quantitative measures of social support and health were obtained at baseline. Sickness absence was followed up for five years. This paper addresses two primary questions. Are higher levels of social support or larger social networks related prospectively to lower rates of short and long spells of sickness absence? Is the chronic stressor of material problems associated prospectively with higher rates of short and long 
spells of sickness absence, and if so, does social support reduce its effect?

A striking gradient in mortality by employment grade was found in the original Whitehall study, ${ }^{15}$ echoed by a gradient in morbidity $^{16}$ and sickness absence in the Whitehall II study. Much of the variation in sickness absence remained unexplained by many relevant factors. ${ }^{17}$ Because we know there are differences in social support between employment grades, we also explored a further question: do differences in social supports help explain grade differences in the rates of short and long spells of absence?

\begin{abstract}
Methods
All non-industrial civil servants aged 35-55 years working in the London offices of 20 departments were invited to participate in the study. The overall response rate was $73 \%$ (74\% for men and $71 \%$ for women). The true response rates are likely to be higher, however, because around $4 \%$ of those on the list of employees had in fact moved before the study and were thus not eligible for inclusion. In total, 10308 civil servants participated, of whom $66.9 \%$ (6895) were men and $33.1 \%$ (3413) were women. Baseline questionnaires and a physical examination were performed and have been reported elsewhere. ${ }^{16}$
\end{abstract}

\section{GRADE OF EMPLOYMENT}

The civil service identifies 12 non-industrial grades on the basis of salary. There was a steep increment in salaries from an annual salary in 1987 of between $£ 3061-£ 5841$ in the clerical and office support grades to between $£ 18020-£ 62100$ in the unified grades $1-6$. Besides the steep increment in salaries there were also appreciable differences in other socioeconomic indicators (education, housing tenure, car ownership, and father's occupation) by grade of employment. ${ }^{16}$

\section{SICKNESS ABSENCE RECORDS}

Ninety three per cent (9564) of participants gave consent to the monitoring of their sickness absence, and of these $96 \%$ (9179) were linked with their record. Computerised sickness absence records to the end of December 1990 were obtained annually from the civil service pay centres. For two thirds of departments, the reason for absence was included. For absences of seven days or less ("short spells"), civil servants were able to complete their own certificate and explain the absence. For absences longer than seven days ("long spells"), a medical certificate was required. Overlapping, consecutive or duplicate spells of sickness absence were merged after taking account of weekends and public holidays. This affected less than $1 \%$ of all spells of sickness absence.

\section{SOCIAL SUPPORT MEASURES}

The qualitative measures included three types of support (confiding/emotional, practical, and negative aspects of support) from the person nominated as closest on the "close persons" questionnaire. ${ }^{10}$ This questionnaire measures perceived support received over the past 12 months. The spouse/cohabitee was named as the closest person for $92 \%$ of married/cohabiting men and $77 \cdot 6 \%$ of married/cohabiting women. Confiding/emotional support is associated with practical support $(r=0.54$ for men; $r=0.49$ for women). However negative aspects of support are minimally associated with confiding/emotional support $(r=-0 \cdot 12$ for men; $r=-0 \cdot 14$ for women) and are not associated with practical support $(r=0.03$ for men; $r=0.05$ for women). Participants could nominate up to four people when answering the close persons questionnaire but we are only presenting data on the first close person.

Quantitative measures of social support were devised from questions about the frequency and number of contacts with relatives, friends, and social groups. ${ }^{1}$ Lack of contact in six spheres of relationships (eg friends) formed an additive score in an "isolation" scale, with a high score reflecting more isolation. Two further scales measure overall numbers of contacts: a "network beyond the household scale" and a "household size scale" capture the social network within and beyond the household. The questions, and the construction of the indices, are obtainable from the second author on request.

\section{CHRONIC STRESSORS MEASURE}

Four questions on difficulties with finances, housing, and neighbourhood difficulties from Pearlin's scale of chronic stressors ${ }^{18}$ formed a scale named "material problems". In our sample these questions loaded on to a single component in a principal components analysis of eight questions from Pearlin's original scale. The proportion with financial difficulties in each employment grade is reported elsewhere. ${ }^{16}$ The proportion with the upper tertile of material problems in each grade was as follows: grade $1,18.4 \%$; grade $2,27 \cdot 2 \%$; grade 3 , $32 \cdot 2 \%$; grade $4,37 \cdot 9 \%$; grade $5,42 \cdot 7 \%$; grade $5,43 \cdot 6 \%$.

\section{STATISTICAL ANALYSIS}

Risk factors, or the magnitude of their effect, for sickness absence may differ for short and long spells, and were thus analysed separately. For each individual the number of prospective spells of sickness absence of each type was computed and the follow up period was measured in person years from the date of screening. Rates of sickness absence were estimated and are expressed per 100 person years. Full details of the statistical methods used for adjusting the rate ratios have been reported previously. ${ }^{17}$

In brief, adjusted rate ratios and their $95 \%$ confidence intervals (95\% CI) were calculated for men and women separately using Poisson regression. ${ }^{1920}$ It was assumed that for each participant the occurrence of short and long spells followed a Poisson distribution. For short spells of sickness absence there was considerable residual variation in excess of the 
Table 1 Numbers and crude rates of short and long spells of sickness absence

\begin{tabular}{|c|c|c|c|c|c|}
\hline & \multirow[b]{2}{*}{ No } & \multicolumn{2}{|c|}{ Short spells $(\leq 7 d)$} & \multicolumn{2}{|c|}{ Long spells $(>7 d)$} \\
\hline & & $\begin{array}{l}\text { No of } \\
\text { spells }\end{array}$ & $\begin{array}{l}\text { Rate of spells (per } \\
100 \text { person years) }\end{array}$ & $\begin{array}{l}\text { No of } \\
\text { spells }\end{array}$ & $\begin{array}{l}\text { Rate of spells (per } \\
100 \text { person years) }\end{array}$ \\
\hline $\begin{array}{l}\text { Men } \\
\text { Women }\end{array}$ & 3086 & 11943 & $119 \cdot 0$ & 1109 & $11 \cdot 1$ \\
\hline
\end{tabular}

Poisson distribution (overdispersion). This overdispersion has no effect on the rate ratio estimates. The estimates of $95 \%$ CIs were, however, adjusted for this overdispersion, approximately doubling the width of the $95 \%$ CIs. For long spells of absence, no overdispersion was detected. The regression models were fitted using the statistical package GLIM. ${ }^{21}$

Analysis has been performed on the $41 \%$ (4202) of participants for whom reason for absence was available and who were administered the social support questionnaire. Fifty five per cent of 10308 participants were not administered versions 3 or 4 of the questionnaire containing the full social support questions or were not in departments for which sickness absence reason data were collected. Only $4.3 \%$ of the total sample were excluded because they missed one or more responses on the questions included in the analyses. We have excluded sickness absence with no recorded reason from this analysis to enable results presented in this paper to be comparable with future analyses looking at the effects of social support on specific reasons for absence.

Poisson regression was used to model the relationship of sickness absence on social support, adjusting for the possible confounding effects of age and grade. First, each of the social support and social network measures was modelled, separately as an independent variable, then with the inclusion of the covariables described below. The three qualitative measures of social support, and the single quantitative measure "network beyond the household" were included in the final model to produce a "full model". In a similar way, the full model for material problems included the covariables, the three closest person measures and the network measure.

To investigate whether the above factors could explain some of the grade difference in sickness absence, social support, material problems, and baseline health covariables were added sequentially to a model which contained grade as a linear term. The percentage change in the estimate for the grade term demonstrated the extent that each factor contributes to the differences across grade.
COVARIABLES AND MEASURES OF ILL HEALTH A series of covariables with potential to influence the association between sickness absence, social support, and material problems were included. Age, employment grade, and marital status were included as basic demographic variables. Grade is unequivocally linked to both social support and sickness absence while marital status is strongly linked to social support. Self reported alcohol consumption in the past year was included as it is associated with sickness absence and possibly social support.

Pre-existing psychological and physical ill health and social support at baseline may influence each other and the risk of future sickness absence. They may also partly act as a measure of current ill health. Baseline physical health was taken into account by using overall health status and recurrent health problems in the past year. Baseline psychological ill health, measured by the general health questionnaire (GHQ) score $^{22}$ was entered as a discrete variable.

All analyses were done separately for men and women, as social support functions and rates of sickness absence differ markedly between men and women. Further details of the measurement of the covariables may be found elsewhere. ${ }^{162324}$

\section{Results}

RATES OF SICKNESS ABSENCE

Table 1 shows the number and rates of short and long spells of sickness absence for men and women. The rates of short spells were much higher than for long spells.

\section{EFFECTS OF COVARIABLES}

The covariables included as adjustments in the full models had independent effects on sickness absence after adjusting for age and grade. Marital status was related to both short and long spells of absence, and the differences were more apparent for men than for women (table 2). Married/cohabiting men and women experienced lower rates of short spells of absence than other men and women; widowers had the highest rates of absence for both short and long spells. In women who do not drink alcohol there was increased risk of both short and long spells of absence compared with one or two drinks per week as baseline. ${ }^{24}$ For men there was an increased risk of long spells of sickness absence in non-drinkers and in those drinking daily or more.

Table 2 Rate ratios (95\% confidence intervals) for short ( $<7$ d) and long spells ( $\geq 7 d$ ) of sickness absence by marital status, in men and women adjusted for age and grade

\begin{tabular}{|c|c|c|c|c|c|}
\hline Marital status & & $\begin{array}{l}\text { Married/ } \\
\text { cohabiting }\end{array}$ & Single & $\begin{array}{l}\text { Divorced/ } \\
\text { separated }\end{array}$ & Widowed \\
\hline Short & $\begin{array}{l}\text { Male } \\
\text { Female } \\
\text { Male } \\
\text { Female }\end{array}$ & $\begin{array}{l}1 \\
1 \\
1 \\
1\end{array}$ & $\begin{array}{l}1.11(1.00,1.23)^{*} \\
1.03(0.91,1.17) \\
0.78(0.64,0.94)^{*} \\
0.86(0.73,1.02)\end{array}$ & $\begin{array}{l}1.11(0.95,1.29) \\
1.11(0.96,1.28) \\
1.00(0.77,1.29) \\
1.10(0.93,1.31)\end{array}$ & $\begin{array}{l}1.60(1.08,2.35)^{*} \\
1.16(0.87,1.54) \\
1.23(0.61,2.48) \\
1.04(0.74,1.46)\end{array}$ \\
\hline
\end{tabular}

${ }^{*} \mathrm{p}<0 \cdot 5$. 
Table 3 Rate ratios (95\% confidence intervals) of spells of sickness absence for tertiles of qualitative aspects of social support from "close person 1 "

\begin{tabular}{|c|c|c|c|c|c|c|c|c|}
\hline \multirow{3}{*}{$\begin{array}{l}\text { Aspect of } \\
\text { social support }\end{array}$} & \multirow{3}{*}{ Sex } & \multirow[t]{3}{*}{ Adjustment } & \multicolumn{6}{|c|}{ Spells of sickness absence } \\
\hline & & & \multicolumn{3}{|c|}{ Short } & \multicolumn{3}{|l|}{ Long } \\
\hline & & & Low & Medium & High & Low & Medium & High \\
\hline $\begin{array}{l}\text { Confiding/ } \\
\text { emotional }\end{array}$ & $\mathbf{M}$ & $\begin{array}{l}\text { Age + grade } \\
\text { covariables model } \\
\text { full model } \\
\text { Age + grade } \\
\text { covariables model } \\
\text { full model }\end{array}$ & $\begin{array}{l}1 \\
1 \\
1 \\
1 \\
1 \\
1\end{array}$ & $\begin{array}{l}1.17(1.07,1.27)^{* * *} \\
1.21(1.11,1.33)^{* * *} \\
1.22(1.11,1.33)^{* * *} \\
1.05(0.93,1.19) \\
1.07(0.95,1.22) \\
1.07(0.94,1.21)\end{array}$ & $\begin{array}{l}1.12(1.02,1.23)^{*} \\
1.23(1.11,1.35)^{* * *} \\
1.25(1.12,1.39)^{* * *} \\
1.06(0.93,1.20) \\
1.16(1.02,1.32)^{*} \\
1.16(1.00,1.34)\end{array}$ & $\begin{array}{l}1 \\
1 \\
1 \\
1 \\
1 \\
1\end{array}$ & $\begin{array}{l}1.09(0.95,1.26) \\
1.08(0.93,1.25) \\
1.10(0.94,1.28) \\
1.40(1.20,1.64)^{* * *} \\
1.41(1.20,1.65)^{* * *} \\
1.34(1.14,1.58)^{*}\end{array}$ & $\begin{array}{l}1.18(1.01,1.37)^{*} \\
1.24(1.06,1.45)^{* *} \\
1.31(1.09,1.56)^{* *} \\
1.37(1.17,1.61)^{* * *} \\
1.50(1.27,1.78)^{*} \\
1.42(1.18,1.70)^{*}\end{array}$ \\
\hline Practical & $M$ & $\begin{array}{l}\text { Age }+ \text { grade } \\
\text { covariables model } \\
\text { full model }\end{array}$ & $\begin{array}{l}1 \\
1 \\
1\end{array}$ & $\begin{array}{l}1.05(0.96,1.15) \\
1.09(0.99,1.20) \\
1.03(0.94,1.14)\end{array}$ & $\begin{array}{l}1.05(0.96,1.14) \\
1.09(0.99,1.20) \\
0.99(0.89,1.10)\end{array}$ & $\begin{array}{l}1 \\
1 \\
1\end{array}$ & $\begin{array}{l}0.99(0.85,1.15) \\
0.94(0.80,1.10) \\
0.88(0.75,1.03)\end{array}$ & $\begin{array}{l}1.09(0.95,1.26) \\
0.99(0.84,1.16) \\
0.86(0.72,1.02)\end{array}$ \\
\hline & $\mathrm{F}$ & $\begin{array}{l}\text { Age }+ \text { grade } \\
\text { covariables model } \\
\text { full model }\end{array}$ & $\begin{array}{l}1 \\
1 \\
1\end{array}$ & $\begin{array}{l}0.98(0.87,1.10) \\
1.00(0.89,1.13) \\
0.98(0.86,1.10)\end{array}$ & $\begin{array}{l}1.12(0.99,1.26) \\
1.08(0.95,1.22) \\
1.02(0.89,1.17)\end{array}$ & $\begin{array}{l}1 \\
1 \\
1\end{array}$ & $\begin{array}{l}1.25(1.08,1.45)^{* *} \\
1.23(1.06,1.43)^{* *} \\
1.15(0.99,1.34)\end{array}$ & $\begin{array}{l}0.86(0.12,1.02) \\
1.40(1.20,1.63)^{* * *} \\
1.23(1.06,1.43)^{* * *} \\
1.13(0.95,1.34)\end{array}$ \\
\hline Negative & $M$ & $\begin{array}{l}\text { Age + grade } \\
\text { covariables model } \\
\text { full model } \\
\text { Age }+ \text { grade } \\
\text { covariables model } \\
\text { full model }\end{array}$ & $\begin{array}{l}1 \\
1 \\
1 \\
1 \\
1 \\
1 \\
1\end{array}$ & $\begin{array}{l}1.01(0.92,1.10) \\
0.98(0.90,1.07) \\
0.98(0.89,1.07) \\
1.14(1.01,1.28)^{*} \\
1.07(0.95,1.21) \\
1.09(0.96,1.23)\end{array}$ & $\begin{array}{l}1.12(1.03,1.22)^{* *} \\
1.03(0.95,1.13) \\
1.04(0.96,1.14) \\
1.14(1.01,1.28)^{*} \\
1.04(0.92,1.18) \\
1.08(0.95,1.22)\end{array}$ & $\begin{array}{l}1 \\
1 \\
1 \\
1 \\
1 \\
1\end{array}$ & $\begin{array}{l}1.27(1.10,1.48)^{* *} \\
1.17(1.01,1.36)^{*} \\
1.20(1.04,1.40)^{*} \\
0.89(0.77,1.04) \\
0.85(0.72,0.99)^{*} \\
0.87(0.75,1.02)\end{array}$ & $\begin{array}{l}1.31(1 \cdot 14,1.52)^{* * *} \\
1.11(0.96,1.29) \\
1.19(1.02,1.38)^{*} \\
1.08(0.93,1.25) \\
0.98(0.84,1.14) \\
1.04(0.89,1.21)\end{array}$ \\
\hline
\end{tabular}

$* \mathrm{p}<0.05 ;{ }^{* *} \mathrm{p}<0.01 ; * * * \mathrm{p}<0.001$

Covariables/ill-health model includes, age, grade, marital status, general health questionnaire, recurrent health problems in the past year, health in the past year, and frequency of alcohol consumption in the past year.

Full model includes the covariables above plus the three "close person 1" measures (confiding/emotional, practical, negative) and the network beyond the household.

\section{EFFECTS OF ILL HEALTH}

Mental ill health, as measured by general health questionnaire caseness, and poor baseline health status, measured as overall health status and recurrent health problems, were related to higher rates of sickness absence. ${ }^{17}$ Higher levels of social suport have also been related to better baseline overall health status and lower baseline GHQ scores.

EFFECTS OF SOCIAL SUPPORTS

Table 3 shows the results of the modelling for qualitative aspects of social support. Contrary to expectations, higher levels of confiding/emotional support from the closest person were followed by higher rates of sickness absence for both men and women for long spells, and for short spells in men. When the models were adjusted for physical and psychological ill health and the covariables, this relationship generally increased. Higher levels of practical support from the closest person were associated with higher rates of long spells for women even after adjusting for ill health and the covariables. As expected, higher levels of negative aspects of social support were associated with increased sickness absence for both short and long spells in men, and for short spells in women. Adjustment for baseline mental and physical health, which may be measuring both preexisting ill health and current ill health, attenuated or removed these effects.

When all three "closest person" measures, and the "network beyond the household" measure were put into the model, there was little change in the results. Confiding/emotional support remained statistically significantly associated with increased short spells in men and increased long spells in men and women. The effects of practical support for women were diminished once the other social supports were taken into account. Negative aspects of support remained statistically associated with higher levels of long spells in men. As these models differed very little whether grade was included or not, only age and grade adjusted models are presented here. We examined the interaction between type of support, for married and nonmarried groups, and sickness absence. There was a single statistically significant interaction for confiding/emotional support in men for long spells which did not show a consistent pattern.

In order to test whether the observed effects could be secondary to existing illness, we repeated the analyses for a "healthy" subgroup. Selection for this group was based on health status "average or good" and GHQ scores less than five. In a "full model" analysis, there was no difference in the pattern of results from those presented here.

\section{EFFECTS OF SOCIAL NETWORKS}

Table 4 shows the results of the modelling for the quantitative dimensions of social support. Because isolation and the other two measures shared some common questions, they were not included together in a model. These quantitative measures of social support showed few statistically significant effects. Unexpectedly, increasing levels of isolation were associated with lower rates of sickness absence for long spells in both men and women. Similarly, a larger social network beyond the household for women, was associated with an increase in the rate of long spells of sickness absence. This association remained after including the three qualitative measures of support. In the analysis for the "healthy" subgroup, there was little difference from the overall population except for long spells, where there was some reduction in the effect of larger network size.

\section{COMPARISON OF RESULTS WITH SAMPLE} WITHOUT REASONS FOR ABSENCE DATA Analyses in this paper are based on the $41 \%$ (4202) of participants where reason for absence was collected and who completed the social supports questionnaire. We have based our analysis on this sample as in future papers we plan to make comparisons with effects of social supports on specific reasons for absence. 
Table 4 Rate ratios (95\% confidence intervals) of spells of sickness absence for tertiles of social networks and material problems

\begin{tabular}{|c|c|c|c|c|c|c|c|c|}
\hline \multirow{3}{*}{$\begin{array}{l}\text { Aspect of } \\
\text { social support }\end{array}$} & \multirow{3}{*}{ Sex } & \multirow[t]{3}{*}{ Adjustment } & \multicolumn{6}{|c|}{ Spells of sickness absence } \\
\hline & & & \multicolumn{3}{|l|}{ Short } & \multicolumn{3}{|l|}{ Long } \\
\hline & & & Low & Medium & High & Low & Medium & High \\
\hline Isolation & $\mathbf{M}$ & $\begin{array}{l}\text { Age }+ \text { grade } \\
\text { covariables model } \\
\text { Age }+ \text { grade } \\
\text { covariables model }\end{array}$ & $\begin{array}{l}1 \\
1 \\
1 \\
1\end{array}$ & $\begin{array}{l}1.08(0.99,1.18) \\
1.08(0.99,1.18) \\
1.07(0.94,1.21) \\
1.10(0.96,1.25)\end{array}$ & $\begin{array}{l}1.09(1.00,1 \cdot 19) \\
1.03(0.94,1.12) \\
0.99(0.88,1.12) \\
0.98(0.86,1.11)\end{array}$ & $\begin{array}{l}1 \\
1 \\
1 \\
1\end{array}$ & $\begin{array}{l}0.91(0.79,1.05) \\
0.92(0.79,1.06) \\
0.83(0.71,0.97)^{*} \\
0.86(0.73,1.01)\end{array}$ & $\begin{array}{l}0.93(0.80,1.07) \\
0.90(0.77,1.04) \\
0.82(0.70,0.95)^{* *} \\
0.82(0.71,0.95)^{* *}\end{array}$ \\
\hline $\begin{array}{l}\text { Network } \\
\text { beyond the } \\
\text { household }\end{array}$ & $\mathbf{M}$ & $\begin{array}{l}\text { Age + grade } \\
\text { covariables model } \\
\text { full model } \\
\text { Age + grade } \\
\text { covariables model } \\
\text { full model }\end{array}$ & $\begin{array}{l}1 \\
1 \\
1 \\
1 \\
1 \\
1\end{array}$ & $\begin{array}{l}1.05(0.96,1.15) \\
1.06(0.97,1.15) \\
1.04(0.95,1.13) \\
1.06(0.94,1.19) \\
1.09(0.97,1.22) \\
1.09(0.96,1.22)\end{array}$ & $\begin{array}{l}0.97(0.89,1.06) \\
1.01(0.93,1.11) \\
0.99(0.90,1.08) \\
1.00(0.88,1.14) \\
1.05(0.93,1.19) \\
1.04(0.92,1.19)\end{array}$ & $\begin{array}{l}1 \\
1 \\
1 \\
1 \\
1 \\
1 \\
1\end{array}$ & $\begin{array}{l}0.93(0.80,1.08) \\
0.93(0.80,1.08) \\
0.91(0.78,1.06) \\
1.24(1.07,1.43)^{* *} \\
1.26(1.09,1.47)^{* *} \\
1.23(1.06,1.43)^{* *}\end{array}$ & $\begin{array}{l}1.07(0.92,1.23) \\
1.15(0.99,1.33) \\
1.12(0.97,1.30) \\
1.15(0.98,1.35) \\
1.23(1.05,1.44)^{*} \\
1.18(1.01,1.39)^{*}\end{array}$ \\
\hline $\begin{array}{l}\text { Household } \\
\text { size }\end{array}$ & $\begin{array}{l}\mathbf{M} \\
\mathbf{F}\end{array}$ & $\begin{array}{l}\text { Age + grade } \\
\text { covariables model } \\
\text { Age + grade } \\
\text { covariables model }\end{array}$ & $\begin{array}{l}1 \\
1 \\
1 \\
1 \\
1\end{array}$ & $\begin{array}{l}1.09(0.96,1.22) \\
0.82(0.75,0.89)^{* * *} \\
0.81(0.72,0.92)^{* * *} \\
0.90(0.80,1.00) \\
0.92(0.77,1.09)\end{array}$ & $\begin{array}{l}1.04(0.92,1.19) \\
0.88(0.75,1.02) \\
0.84(0.72,1.00) \\
0.87(0.71,1.06) \\
0.89(0.72,1.10)\end{array}$ & $\begin{array}{l}1 \\
1 \\
1 \\
1 \\
1\end{array}$ & $\begin{array}{l}1.23(1 \cdot 06,1 \cdot 43)^{* *} \\
1.00(0.85,1.17) \\
0.87(0.71,1.08) \\
1.03(0.89,1.18) \\
1.09(0.88,1.35)\end{array}$ & $\begin{array}{l}1.18(1.01,1.39)^{*} \\
1.15(0.89,1.48) \\
0.99(0.75,1.30) \\
1.11(0.88,1.41) \\
1.21(0.93,1.57)\end{array}$ \\
\hline $\begin{array}{l}\text { Material } \\
\text { problems }\end{array}$ & $\mathbf{M}$ & $\begin{array}{l}\text { Age + grade } \\
\text { covariables model } \\
\text { full model } \\
\text { Age + grade } \\
\text { covariables model } \\
\text { full model }\end{array}$ & $\begin{array}{l}1 \\
1 \\
1 \\
1 \\
1 \\
1 \\
1\end{array}$ & $\begin{array}{l}0.99(0.90,1.09) \\
0.95(0.86,1.04) \\
0.94(0.86,1.03) \\
1.13(0.99,1.28) \\
1.08(0.95,1.24) \\
1.09(0.95,1.24)\end{array}$ & $\begin{array}{l}1.09(1.01,1.19)^{*} \\
1.00(0.91,1.08) \\
1.00(0.91,1.09) \\
1.30(1.16,1.46)^{* * *} \\
1.18(1.04,1.33)^{* *} \\
1.19(1.05,1.35)^{* *}\end{array}$ & $\begin{array}{l}1 \\
1 \\
1 \\
1 \\
1 \\
1\end{array}$ & $\begin{array}{l}1.03(0 \cdot 88,1.20) \\
0.99(0 \cdot 85,1.16) \\
0.99(0.85,1.16) \\
1.00(0 \cdot 85,1.18) \\
0.95(0 \cdot 80,1.12) \\
0.93(0 \cdot 79,1.10)\end{array}$ & $\begin{array}{l}1.18(1.02,1.35)^{*} \\
1.02(0.89,1.18) \\
1.01(0.88,1.17) \\
1.27(1.10,1.47)^{* *} \\
1.16(1.00,1.34) \\
1.15(0.99,1.34)\end{array}$ \\
\hline
\end{tabular}

${ }^{*} \mathrm{p}<0.05 ;{ }^{* *} \mathrm{p}<0.01 ; * * * \mathrm{p}<0.001$

Covariables/ill-health model includes, age, grade, marital status, general health questionnaire, recurrent health problems in the past year, health in the past year, and frequency of alcohol consumption in the past year.

Full model includes the covariables above plus the three "close person 1" measures (confiding/emotional, practical, negative) and the network beyond the household.

We were able to test the robustness of our findings by comparing results with the subsample of 2117 respondents in departments that did not record detailed reasons for absence. In general, the rate ratios for this sample without reason data were similar to those presented in tables 3 and 4 and thus we have not included these results. However, the results differed for both confiding/emotional support and isolation for women. In women, in the subsample of 2117 , higher levels of confiding/emotional support were followed by lower rates of spells of sickness absence (rate ratios for high versus low tertiles: short spells 0.91 ; long spells 0.81 ), although these failed to reach statistical significance. Intermediate levels of isolation in women were significantly related to higher rates of long spells (rate ratio for medium versus low: $1 \cdot 30$ ).

We investigated various possible explanations for these inconsistent findings. First, whether differences in the grade distribution by department would result in different patterns of sickness absence by grade within departments. There were differences by department in sickness absence rates and in the strength of the grade gradients in sickness absence rates. We allowed for this by adjusting for a department effect and also by adjusting for grade within departments. This made little difference to the rate ratios for confiding/emotional support. Secondly, we checked and confirmed that the distribution of scores within the tertiles of confiding/emotional support were similar for the two samples with and without reasons. Thirdly, we checked that the distribution across marital status was similar for both samples. Overall, there was no obvious explanation for these differences between the two samples.

CHRONIC STRESSORS AND SICKNESS ABSENCE Men and women reporting the highest tertile of material problems, our measure of chronic stressors (bottom of table 4), had higher rates of sickness absence for both short and long spells. This effect was progressively attenuated when adjusted for age, grade, marital status mental and physical ill health, and alcohol use but it remained statistically significant for short spells in women. Further adjustment for the social support measures in the full model had little impact once the confounding variables had been taken into account.

The buffering hypothesis, tested by examining for interaction between material problems and social support showed distinctive patterns of sickness absence by tertiles of social support. Table 5 shows that for men material problems tended to increase the risk of long spells of sickness absence for those reporting low or medium levels of practical support but not for those reporting high levels of practical support. Similarly, the rate ratios for short spells of sickness absence in men (not shown) were significantly reduced as levels of practical support were increased - this was the only significant interaction for short spells. In women, high levels of material problems were consistently associated with higher rates of long spells only for those women reporting medium or high levels of negative aspects of support and intermediate levels of confiding/emotional support. There was no interaction between the effect of material problems and the social network measures on long spells of sickness absence in either men or women.

\section{SOCIAL SUPPORT AN EXPLANATION OF THE GRADE EFFECT}

There was a strong employment grade gradient in rates of both short and long spells of absence in men and women. The rate ratio for the lowest grade compared with the top grade was $6 \cdot 1$ for short spells and $6 \cdot 6$ for long spells in men. The corresponding figures for women were $3 \cdot 2$ and $3 \cdot 7$.

Social support, especially confiding/emotional support, decreases from higher to lower 
Table 5 Rate ratios of long spells of sickness absence for material problems within tertiles of social support measures

\begin{tabular}{|c|c|c|c|c|c|c|c|c|c|}
\hline \multicolumn{2}{|c|}{ Aspect of social support } & \multicolumn{8}{|c|}{ Spells of sickness absence } \\
\hline & & \multicolumn{4}{|l|}{ Men } & \multicolumn{4}{|c|}{ Women } \\
\hline & & \multicolumn{4}{|c|}{ Material problems } & \multicolumn{4}{|c|}{ Material problems } \\
\hline & & Low & Medium & High & $\begin{array}{l}\text { Significance of } \\
\text { interaction term }\end{array}$ & Low & Medium & High & $\begin{array}{l}\text { Significance of } \\
\text { interaction term }\end{array}$ \\
\hline \multirow{2}{*}{$\begin{array}{l}\text { Confiding/ } \\
\text { emotional }\end{array}$} & Low & 1 & $1.12(0.84,1.50)$ & $0.92(0.71,1.20)$ & \multirow[b]{2}{*}{$\mathrm{p}<0.05$} & 1 & $0.76(0.53,1.10)$ & $1.09(0.82,1.40)$ & \multirow[b]{2}{*}{$\mathrm{p}<0.01$} \\
\hline & $\begin{array}{l}\text { Medium } \\
\text { High }\end{array}$ & $\begin{array}{l}1 \\
1\end{array}$ & $\begin{array}{l}0.88(0.68,1.13) \\
1.03(0.78,1.35)\end{array}$ & $\begin{array}{l}1.19(0.95,1.50) \\
0.90(0.71,1.16)\end{array}$ & & 1 & $\begin{array}{l}1.14(0.86,1.50) \\
0.90(0.70,1.20)\end{array}$ & $\begin{array}{l}1.58(1.23,2.00) \\
0.85(0.66,1.10)\end{array}$ & \\
\hline \multirow[t]{3}{*}{ Practical } & Low & 1 & $0.69(0.50,0.95)$ & $1.10(0.86,1.41)$ & \multirow{3}{*}{$\mathrm{p}<0.01$} & i & $0.78(0.58,1.00)$ & $1.22(0.95,1.60)$ & \multirow{3}{*}{ NS } \\
\hline & Medium & i & $1.39(1.06,1.81)$ & $1.13(0.88,1.47)$ & & 1 & $0.97(0.73,1.30)$ & $1.06(0.83,1.40)$ & \\
\hline & High & $i$ & $0.91(0.71,1.17)$ & $0.86(0.68,1.08)$ & & 1 & $1.10(0.82,1.50)$ & $1.14(0.87,1.50)$ & \\
\hline \multirow{3}{*}{ Negative } & Low & 1 & $1.02(0.79,1.33)$ & $0.95(0.73,1.23)$ & \multirow{3}{*}{ NS } & 1 & $0.78(0.61,0.99)$ & $0.83(0.65,1.05)$ & \multirow{3}{*}{$\mathrm{p}<0.01$} \\
\hline & Medium & 1 & $1.04(0.79,1.37)$ & $1.19(0.94,1.52)$ & & 1 & $0.94(0.68,1.29)$ & $1.23(0.94,1.62)$ & \\
\hline & High & 1 & $0.89(0.68,1.18)$ & $0.89(0.70,1 \cdot 14)$ & & 1 & $1.32(0.93,1.85)$ & $1.68(1.26,2 \cdot 25)$ & \\
\hline \multirow{3}{*}{$\begin{array}{l}\text { Network } \\
\text { beyond the } \\
\text { household }\end{array}$} & Low & 1 & $0.83(0.62,1.11)$ & $1.00(0.77,1.29)$ & \multirow{3}{*}{ NS } & 1 & $0.73(0.53,0.99)$ & $0.93(0.72,1.21)$ & \multirow{3}{*}{ NS } \\
\hline & Medium & 1 & $1.08(0.81,1.44)$ & $1.13(0.88,1.44)$ & & 1 & $1.03(0.79,1.34)$ & $1.30(1.02,1.66)$ & \\
\hline & High & 1 & $1.05(0.82,1.34)$ & $0.93(0.74,1.17)$ & & 1 & $1.06(0.77,1.44)$ & $1.22(0.93,1.59)$ & \\
\hline
\end{tabular}

All models are fully adjusted (including age, grade, marital status, general health questionnaire, recurrent health problems in the past year, frequency of alcohol consumption in past year, social support measures, network beyond household and include an interaction term between material problems and the social support network measure.

grades. However, social supports, social networks, and material problems explained little of the grade effect beyond that explained by the baseline health measures. The addition of these baseline health measures reduced the grade effect on sickness absence for women by one quarter and for men by one tenth; there was little difference for short and long spells. Beyond this, the addition of qualitative social supports and material problems made a negligible reduction in the estimate for grade.

\section{Discussion}

In this prospective study of a cohort of British civil servants, positive aspects of social support were found to be a small predictor of increased rates of spells of sickness absence. Increased levels of confiding/emotional support from the closest person were associated with higher rates of both short and long spells of sickness absence, although this was not consistent for women in the sample without reasons for sickness absence. There is thus a question as to how robust this finding may be. Nevertheless, this effect was echoed in the quantitative measures, where, for long spells, those with less isolation, and women who reported increased network size, all had higher rates. In view of the number of comparisons made it is quite likely that some of the statistically significant associations may have occurred by chance.

The association of increased sickness absence with higher levels of emotional support was, at first sight, unexpected, as social support has been associated with lower mortality, ${ }^{25}$ lower morbidity, ${ }^{26}$ and greater well being. ${ }^{27}$ However, it is also possible that social support influences health indirectly through an influence on behaviour - the "social influence" model ${ }^{28}$ Sickness absence obviously reflects illness: higher ratios were seen for those with pre-existing ill health at baseline. Ill health at baseline may also be a crude measure of current ill health. Thus, the adjustment for baseline ill health in the covariables/ill health model is also a way of asking whether social support affects the "illness behaviour" aspects of sickness absence other than through its effect on health. The rate ratios for confiding/emotional support increasing after adjusting for "ill health" suggests this type of support has an effect on "illness behaviour" and not on illness directly. This effect is not confined to minor illness, as it is found for rates of both long and short spells. Sickness absence is a complex phenomenon as it indicates not only illness, but also a way of coping with illness. ${ }^{29}$ Emotional support may increase self esteem and sense of control and allow people the confidence to take time off when ill. ${ }^{28}$ Emotional support may also facilitate active coping with illness, ${ }^{30}$ part of which may be taking sick leave. This is likely to be adaptive behaviour, where an ill person recognises their illness, and chooses to recuperate away from work. In people with high levels of emotional support, this behaviour may be legitimated and encouraged. The tendency to attend work or take sickness absence, in the presence of illness, is also likely to be influenced by the potentially conflicting forces of the attractiveness of work and home, and feelings of obligation to work and home responsibilities. It may also be that high levels of personal support at home are accompanied by more social obligations at home and a greater likelihood of taking time off work; this explanation is more likely because the effect is stronger in women. ${ }^{31}$ But in our study this does not seem to reflect taking off more time to look after young children. ${ }^{32}$

On the other hand high negative aspects of support, which predicted higher rates of long spells of sickness absence for men may represent a different phenomenon; that negative aspects of support cause illness and increased rates of sickness absence. It could be argued that the association merely reflects response bias, where illness colours perception of relationships. Indeed, adjustment for baseline psychological and physical health diminished the association a little, suggesting that perceptions of negative aspects of support are influenced to a degree by existing illness. But this is unlikely to be a full explanation, because the same finding was also apparent in the "healthy" subgroup where perceptions of negative aspects of support from the closest person would not have been so influenced by existing ill health. 
We expected that people reporting the least social network contacts would have higher rates of spells of sickness absence. This was not found: in both the isolation and the network beyond the household measures, lower frequencies and/or numbers of contacts were related to lower rates of long spells of sickness absence. The degree of social isolation reflected in this group is not extreme: civil servants in this study were all integrated socially at least to the extent of having a job. Nevertheless, one would not expect the most isolated to be the healthiest. ${ }^{1}$ Civil servants who lack social contact outside work may tend to remain at work despite illness. Isolated workers may be more vulnerable to being stigmatised for taking time off, and at the same time, more reliant on work for both job security and support.

It may be argued that high levels of confiding/ emotional and practical support and social network contact are secondary to existing ill health, ${ }^{33}$ that is, more support is elicited by those who are ill. In our data, this seems unlikely, as the effects are still found after rigorous adjustment for baseline ill health and in the subsample chosen to be free of ill health at baseline.

\section{SICKNESS ABSENCE AS COPING BEHAVIOUR}

We found, as others have, that rates of sickness absence were higher for women than for men. Some of this difference is related to the different grade distributions in men and women. The remaining differences however, cannot be explained in this cohort by women taking more time off than men to look after young children. ${ }^{32}$ We suggest that women, by more readily taking absence for illness, may be coping adaptively. It is well known that women take more care of their health, tend to be more aware of illness ${ }^{34}$ and consult health services more than men. ${ }^{35}$ There is also evidence that men often deny ill health. Thus, when women are absent from work, they may be behaving more "healthily" than men who ignore ill health and work despite it. This explanation is in keeping with gender differences in mortality rates, ${ }^{36}$ in view of the paradox of women's higher rates of sickness absence but their lower mortality rates.

\section{GRADE EFFECTS}

As the quality of relationships differed by employment grade, we might expect that social support would contribute to the disparity in sickness by grade. We found that, although social support independently predicted sickness absence, it made little contribution to explaining the employment grade gradient in sickness absence. The baseline physical health, mental health, and alcohol consumption measures, explained the influence of grade on sickness absence more powerfully than either social supports or material problems.

CHRONIC STRESSORS

Much attention has been given to the possible role that social support may play in buffering the effect of stressors. ${ }^{113}$ We found that ma- terial problems did increase rates of sickness absence. However, once the confounding variables of baseline mental and physical ill health and alcohol use had been taken into account, the effect of material problems was diminished. We concluded that material problems do affect sickness absence and that this effect is mediated through ill health. When we included both social support and material problems at the same time in the full model there were no changes in the estimates of the coefficients. However, there was an interaction between material problems and social support; the effect of material problems on long spells of sickness absence was diminished by practical support in men and increased by negative aspects of support in women. Thus although social support may not exert a direct effect on sickness absence independent of material problems, there does seem to be some evidence, if somewhat contradictory, that it may moderate or buffer the effect of these chronic stressors on sickness absence.

\section{LIMITATIONS}

This cohort of non-industrial civil servants may differ from the private sector in terms of corporate culture, including attitudes towards sickness absence, and how social support may influence it. Nevertheless, overall rates of sickness absence in the civil service are similar to those observed in other British organisations ${ }^{37}$ and it is likely, at the very least, to be similar to other office based white collar organisations in the public sector.

We tested the robustness of our findings by comparison with respondents in departments that did not record detailed reasons for sickness absence. The findings were largely consistent except for confiding/emotional support and isolation for women. We found no explanation for this in terms of differences in the distribution of employment grade, social support, or marital status between the two samples. The effects of social supports are relatively small compared with grade effects and there may be some complex interaction occurring between the work environment and both the reporting of social supports and absence behaviour which accounts for these differences between the two subsamples.

Because the estimates of effects are small, we considered whether the measures or the study design might not have been sensitive enough to capture the subtlety of the relationship. The effects of baseline support may diminish over time because social supports themselves may change. This measurement error may have obscured differences across groups. Preliminary analysis suggests that social support measures did remain moderately consistent across time; groups in which they change may contribute more to our understanding of illness, social support and sickness absence.

\section{FURTHER WORK}

If high levels of support at home encourage absence at times of illness, high levels of support at work, already shown to have a positive effect 
on well being, could have the opposite effect of keeping people at work. There may also be an interaction between work and social support at home, where those who have a poor experience in one domain may be protected by a richer experience in the other. ${ }^{6}$ This can be tested by further analysis in this cohort.

This project was supported by the Institute for Work and Health, Toronto, Canada, and was carried out during Elizabeth Rael's secondment to University College London Medical School. We thank all participating Civil Service departments and their welfare, personnel, and establishment officers, and the Civil Service Central Monitoring Service, the Civil Service Occupational Health Service, Dr George Sorrie, Dr Adrian Semmence, the Council for Civil Service Unions and all participating
civil servants.

We thank Sheena Wakefield for computing support, Julie Moore (project coordinator) and Rob Canner for data management. We thank John Frank for initiating this project, and for his continuing support throughout, and the members of the Whitehall II team for their assistance in making this project happen. We thank Toni Antonucci and Rebecca Fuhrer for happen. We thank Toni Antonucci and Rebecca F

The Whitehall II study is supported by the Medical Research Council, Health and Safety Executive, British Heart Foundation, National Heart Lung and Blood Institute (2 IO HAL36310-04) Agency for Health Care Policy Research (5 ROI H506516) and the John D \& Catherine T MacArthur Foundation Research Network on Successful Midlife Development.

1 Berkman LF, Syme SL. Social networks, host resistance, and mortality: a nine year follow-up study of Alamed County residents. Am $\mathcal{F}$ Epidemiol 1979;109:186-204.

2 Schoenbach VJ, Kaplan BH, Friedman L, Kleinbaum DG Social ties and mortality in Evans County, Georgia. $A m$ f Epidemiol 1986;123:577-91.

3 Welin L, Tibblin G, Svardsudd K, et al. Prospective study of social influences on mortality. Lancet 1985;i:915-8.

4 Orth-Gomer K, Johnson JV. Social network interaction and mortality: a six year follow-up study of a random sample of the Swedish population. $\mathcal{f}$ Chron Dis 1987;40:949-57.

5 Broadhead WE, Kaplan BH, James SA 1987;40:949-57. Broadhead WE, Kaplan BH, James SA, et al. The epi-
demiologic evidence for a relationship between social supdemiologic evidence for a relationship between social

6 Hibbard JH, Pope CR. The quality of social roles as predictors of morbidity and mortality. Soc Sci Med 1993 36(3):217-25.

7 Chevalier A, Luce D, Blanc C, Goldberg M. Sickness absence at the French National Electric and Gas Company. $B r$ F Ind Med 1987;44:101-10.

8 Leigh JP. Employee and job attributes as predictors of absenteeism in a national sample of workers: the importance of health and dangerous working conditions. Soc $S_{c i}$ Med 1991;33:127-37.

9 House JS, Kahn RL. Measures and concepts of social support. In: Cohen C, Syme SL, eds. Social support and health. London: Academic Press, 1985;83-108.

10 Stansfeld S, Marmot M. Deriving a survey measure of socia support: the reliability and validity of the close persons questionnaire. Soc Sci Med 1992;35:1027-35.

11 Cassel J. The contribution of the social environment to host resistance. Am f Epidemiol 1976;104:107-23.

12 Thoits PA. Conceptual, methodological and theoretical problems in studying social support as a buffer against life stress. F Health Soc Behav 1982;23:145-59.

13 Cohen S, Wills TA. Stress, social support and the buffering hypothesis. Psychological Bulletin 1985;98:310-57.

14 Marmot M, Feeney A, Shipley M, North F, Syme SL Sickness absence as a measure of health status and functioning. 7 Epidemiol Community Health 1995;49:124-30.

15 Reid DD, Brett GZ, Hamilton PJS, Jarrett RJ, Keen H, Rose G. Cardio-respiratory disease and diabetes among middle-aged civil servants. Lancet 1974;i:1003-6.

16 Marmot MG, Davey Smith G, Stansfeld S, et al. Health inequalities among British civil servants: the Whitehall II inequalities among British civil serv
study. Lancet 1991;337:1387-93.

17 North F, Syme SL, Feeney A, Head J, Shipley MJ, Marmot MG. Explaining socioeconomic differences in sickness absence: the Whitehall II study. BMF 1993;306:361-6.

18 Pearlin LI, Schooler C. The structure of coping. $\mathcal{f}$ Health Soc Behav 1978;19:2-21.

19 McCullagh P, Nelder JA. Generalised linear models. London: Chapman \& Hall, 1983.

20 Aitken M, Anderson D, Francis B, Hinde J. Statistical modelling in GLIM. New York: Oxford University Press, 1989;217-225.

21 Numerical Algorithms Group. The GLIM System Release 3.77 Manual. Ed 2. Oxford, 1987.

22 Goldberg D. The detection of psychiatric illness by questionnaire. London, Oxford University Press, 1972.

23 Stansfeld SA, Davey Smith G, Marmot MG. Association between physical and psychological morbidity in the Whitehall II study. F Psychosom Res 1993;37:227-38.

24 Marmot MG, North F, Feeney A, Head J. Alcohol consumption and sickness absence: from the Whitehall II study. Addiction 1993;88:369-82.

25 Blazer DG. Social support and mortality in an elderly community population. Am $\mathcal{f}$ Epidemiol 1982;115:684-94.

26 Andrews G, Tennant C, Hewson D, Schonell M. The relation of social factors to physical and psychiatric illness. Am $\mathcal{J}$ Epidemiol 1978;108:27-35.

27 Schaefer C, Coyne JC, Lazarus RS. The health-related functions of social support. $¥$ Behav Med 1981;4:381-406.

28 Cohen S. Psychosocial models of the role of social support in the etiology of physical disease. Health Psychol 1988;7: in the etiolo.

29 Kristensen TS. Sickness absence and work strain among Danish slaughterhouse workers: an analysis of absence from work regarded as coping behaviour. Soc Sci Med 1991;32:15-27.

30 Holahan CJ, Moos RH. Personal and contextual determinants of coping strategies. $\mathcal{F}$ Pers Soc Psychol 1987; 52:946-55.

31 Kessler RC, McLeod JD, Wethington E. The costs of caring: a perspective on the relationship between sex and psychological distress. In: Sarason IG, Sarason BR, eds. Social support: theory, research and applications. Boston: Martinus Nijhoff 1985;491-506.

32 North FM. Work and absence from work. London: University of London, 1990. PhD thesis.

33 Johnson TP. Mental health, social relations, and social selection: a longitudinal analysis. F Health Soc Behav 1991 32:408-23.

34 Ingham JG, Miller P. Consulting with mild symptoms in general practice. Social Psychiatry 1982;17:77-88.

35 Finlay Jones RA, Burvill PW. Contrasting demographic patterns of minor psychiatric morbidity in general practice and the community. Psychol Med 1978;8:455-66.

36 Syme SL. Social epidemiology and the work environment. Int $\mathcal{F}$ Health Serv 1988;18(4):635-45.

37 Confederation of British Industry. Too much time out? $C B I$ Percom survey on absence from work, 1993. London: CBI, 1993. 